\title{
Penerapan Metode Rapid Application Development (RAD) dalam Rancang Bangun Sistem Informasi Rapor Online (SIRALINE)
}

\author{
Nurman Hidayat ${ }^{1}$, Kusuma Hati ${ }^{2}$
}

\begin{abstract}
The report card processing system on Imam Syafi'i Jember Islamic Elementary School still not yet computerized. Report card score processing is still using Microsoft Excel and count it manually. So there can be any mistakes in calculation, and report card processing needs a lot of time. With this online report card information system, hopefully it can make it easier for schools to manage report cards in a way that saves time and effort and avoid miscalculation of report card scores. At this writing, the writer is still using the Rapid Application Development (RAD) method. Applications created using Codeigniter 3 for the framework, PHP for the programming language, MySQL for the database, and Visual Studio Code as tools to help create the information system. This system helps in the processing of report cards to print the results of report cards that are conveyed well and quickly.
\end{abstract}

Intisari - Sistem pengolahan rapor pada SD Islam Imam Syafi'i Jember masih belum terkomputerisasi, yaitu mengola nilai rapor masih menggunakan Microsot Excel dan menghitungnya masih dengan cara manual, sehingga bisa terjadi kesalahan dalam perhitungan dan proses pengolahan rapor membutuhkan waktu yang lama. Dengan adanya sistem informasi rapor online ini, diharapkan dapat mempermudah pihak sekolah dalam mengola rapor dengan cara yang lebih hemat waktu dan tenaga, dan menghindari kesalahan perhitungan nilai rapor. Pada penulisan ini penulis menggunakan metode Rapid Aplication Development (RAD). Aplikasi yang dibuat menggunakan Codeigniter 3 untuk framework, PHP untuk bahasa pemrograman, MySQL untuk database dan Visual Studio Code sebagai tools membantu pembuatan sistem informasi tersebut. Sistem ini membantu dalam proses pengolahan rapor sampai mencetak hasil rapor yang tersampaikan dengan baik dan cepat.

Kata Kunci - Codeigniter, MySQL, PHP, Rapor Online, Sistem Informasi.

\section{PENDAHULUAN}

Teknologi informasi saat ini tidak hanya dimaanfaatkan di perusahaan atau industri saja, tetapi juga di bidang pendidikan. Saat ini sudah banyak sekolah-sekolah yang memanfaatkan perkembangan teknologi untuk memperlancar kegiatan di sekolahnya. Salah satunya adalah memanfaatkan sistem informasi berbasis website. Karena penggunaan sistem informasi berbasis website dapat digunakan banyak orang dan sangat mudah diakses dimana saja dan kapan saja sehingga dapat membantu menyelesaikan suatu perkerjaan.

\footnotetext{
${ }^{1,2}$ Program Studi Sistem Informasi STMIK STMIK Antar Bangsa, Jl. HOS Cokroaminoto Kawasan Bisnis CBD Ciledug , Blok A5, No.29-36, Karang Tengah, Kota Tangerang; Telp. (021) 50986099; e-mail: nurmanhidayat11@gmail.com kusumahati. antarbangsa@gmail.com
}

SD Islam Imam Safi's Jember adalah sekolah dasar swasta yang berlandaskan Al-Qur'an dan Sunnah, dan sudah menerapkan kurikulum 2013. SD Islam Imam Syafi'i juga sudah memiliki website dan fasilitas hotspot yang memudahkan guru dan wali kelas mengakses Internet di lingkungan sekolah. Setiap akhir semester SD Islam Imam Syafi'i melakukan kegiatan evaluasi penilaian untuk melihat perkembangan dari setiap siswa dalam satu semester yang telah ditempuh. Masing-masing guru mata pelajaran memproses nilai dan memberikan hasil nilai akhir mata pelajaran kepada wali kelas. Lalu wali kelas mengumpulkan hasil nilai dan menjadikan satu dokumen hasil nilai akhir tersebut sehingga menjadi satu dokumen yang biasa disebut rapor siswa.

Dari hasil riset yang dilakukan penulis di SD Islam Imam Syafi'i Jember, proses pengolahan rapor yang dilakukan di sekolah tersebut masih bisa dibilang tidak efisien dan kurang efektif. Karena setiap guru mata pelajaran mengola nilai rapor menggunakan excel secara terpisah kemudian diberikan kepada wali kelas untuk disatukan menjadi rapor. Hal ini akan mempersulit wali kelas dalam mengola nilai untuk dijadikan rapor sehingga proses pengolahan rapor menjadi lambat. Belum lagi wali kelas harus berkerja ekstra menentukan deskripsi nilai secara manual berdasarkan nilai dari masingmasing siswa dan masing-masing mata pelajaran yang berbeda beda, dan website disekolah tersebut belum dioptimalkan penggunaannya.

Dari masalah diatas yang telah dijelaskan, maka diperlukan sebuah solusi untuk mempermudah proses pengolahan rapor dengan cara membuat sistem informasi pengolahan rapor secara online di SD Islam Imam Syafi'i. Dengan menggunakan aplikasi pengolahan rapor berbasis website, penggunaan diharapkan akan lebih mudah mengelolah rapor, tidak membutuhkan tenaga ekstra dan dapat mempercepat proses pengolahan rapor setiap akhir semester.

Ruang lingkup sistem yang dirancang hanya dibuat untuk bisa diakses oleh kepala sekolah, admin, wali kelas, dan guru saja. Admin hanya memproses data wali kelas, guru, siswa, mata pelajaran, kelas, kurikulum dan mencetak rapor. Wali kelas hanya memproses pengolahan dan melihat nilai rapor. Guru hanya bisa memasukan nilai akhir siswa. Sedangkan kepala sekolah bisa melihat nilai rapor siswa untuk melihat perkembangan siswa-siswa.

Pada penelitian ini, penulis juga mengacu pada beberapa penelitian sebelumnya, diantaranya adalah penelitian yang dilakukan oleh Nenzy Ahlung Arniyanto Putri dan Anggit Dwi Hartanto, mengenai Sistem Informasi Pengolahan Nilai 
Rapor Pada Siswa SMP Negeri 1 Yogyakarta Berbasis Web, dimana pengolahan nilai di SMP Negeri 1 Yogyakarta mempunyai kelemahan dalam mengolah nilai siswa karena pengolahan nilai yang belum terkomputerisasi (manual). Selain itu pada sistem manual ini masih terdapat beberapa kelemahan, diantaranya masih memerlukan waktu yang lama proses penilaian, sering terjadi kesalahan pada hasil penjumlahan dan sering terjadi kehilangan data. Harapannya dengan menggunakan website rapor ini dapat mempermudah melakukan proses pengelolaan nilai rapor [2].

Penelitian kedua yang terkait dengan penelitian yang dilakukan oleh penulis diantaranya adalah penelitian yang dilakukan oleh Susy Kusuma Wardani, mengenai Sistem Informasi Pengolahan Data Nilai Siswa Berbasis Web Pada Sekolah Menengah Atas (SMA) Muhammadiyah Pacitan, dimana Sistem pengolahan data nilai siswa SMA Muhammadiyah Pacitan belum sepenuhnya terkomputerisasi. Berkas penilaian siswa dari guru mata

\section{TEORI PENDUKUNG}

\section{A. Konsep Dasar Sistem Informasi}

Suatu sistem di dalam organisasi yang mempertemukan kebutuhan pengelolaan transaksi harian, mendukung kegiatan operasional dan manajerial, serta kegiatan strategi dari suatu organisasi dan menyediakan pihak tertentu dengan laporanlaporan yang dibutuhkan, disebut sistem informasi [1]. Dalam sistem informasi terdapat komponen yang disebut blok bangunan (building block) yaitu [1] :

1. Blok Masukan (Input Block)

Mewakili data yang masuk ke dalam sistem informasi.

2. Blok Model (Model Block)

Terdiri dari kombinasi prosedur, logika dan metode matematik yang mengelola data input dan data yang tersimpan di basis data dengan cara yang sudah ditentukan untuk menghasilkan keluaran yang diinginkan.

3. Blok Keluaran (Output Block)

Suatu bentuk informasi yang berkualitas dan dokumentasi yang berguna untuk semua tingkatan manajemen dan semua pemakai sistem.

4. Blok Teknologi (Technologi Block)

Berfungsi menerima input, menjalankan model, dan menyimpan serta mengakses data, menghasilkan dan mengirimkan keluaran dan juga membantu pengendalian diri secara keseluruhan.

5. Blok Basis Data (Database Block)

Merupakan kumpulan data yang saling berhubungan dan tersimpan diperangkat keras komputer serta memerlukan penggunan perangkat lunak untuk memanipulasinya.

6. Blok Kendali (Control Block)

Digunakan untuk mengendalikan faktor-faktor yang dapat merusak sistem informasi. Pengendalian perlu dirancang agar hal-hal yang dapat merusak sistem dapat dicegah, atau bila terlanjur terjadi kesalahan maka dapat langsung diatasi.

\section{B. Definisi Nilai}

Nilai merupakan rujukan dan keyakinan dalam menentukan pilihan. Nilai juga dapat diartikan sebagai patokan normative yang dapat mempengarui manusia dalam menentukan pilihan. Nilai dapat dikatakan sesuatu yang menyenangkan kita, nilai identik dengan apa yang di inginkan, nilai merupakan sarana pelatihan kita. Nilai juga diartikan sebagai harga, dalam hal ini adalah suatu angka kepandaian [2].

\section{Definisi Rapor}

Rapor merupakan buku yang berisi nilai kepandaian dan prestasi belajar murid di sekolah. Rapor ini berfungsi sebagai laporan resmi guru kepada orangtua atau wali murid. Rapor merupakan salah satu bentuk pertanggung jawaban sekolah terhadap masyarakat tentang kemampuan yang dimiliki siswa berupa sekumpulan hasil penilaian [2].

\section{METODE PENELITIAN}

Metode penelitian adalah tahapan atau langkah yang dilakukan oleh peneliti dalam rangka untuk mengumpulkan informasi atau data serta melakukan investigasi pada data yang telah didapatkan [3]. Metode penelitian dalam penelitian ini meliputi :

A. Teknik Pengumpulan Data

Teknik pengumpulan data yang dilakukan pada penelitian ini meliputi :

1. Observasi

Dilakukan untuk mencari dan mengumpulkan data dengan meneliti dokumen-dokumen yang berhubungan dengan siswa, guru, wali kelas, mata pelajaran, penilaian, kurikulum yang ada untuk mengetahui sistem yang sedang digunakan. Observasi dilaksanakan di SD Islam Imam Syafi'i Jember.

2. Wawancara

Mengumpulkan data-data dengan mewawancarai kepala sekolah, bagian akademik dan tata usaha di SD Islam Imam Syafi'i, dan juga agar mengetahui kebutuhan apa saja yang diperlukan dari pihak sekolah sehingga dapat dibuatkan sistem informasi yang sesuai.

3. Studi Pustaka

Dilakukan dengan cara membaca dan mempelajari literatur, buku-buku, serta mengumpulkan artikel-artikel dari Internet yang mendukung tema yang akan dibahas didalam penulisan ini.

B. Model Pengembangan Sistem

Model pengembangan sistem yang digunakan dalam penelitian ini adalah Rapid Aplication Development (RAD) yang merupakan salah satu model dari System Development Life Cycle (SDLC) [4]. Rapid Aplication Development (RAD) merupakan model proses pengembangan perangkat lunak secara linear sequential yang menekankan pada siklus pengembangan yang sangat singkat [5]. RAD dapat dijadikan acuan untuk mengembangkan suatu sistem informasi yang unggul dalam hal kecepatan, ketepatan dan biaya yang lebih rendah [6]. 
Alasan penggunaan pendekatan Rapid Aplication Development (RAD) karena pendekatan ini memiliki kelebihan, diantaranya adalah : siklus pengembangan lebih pendek, lebih fleksibel, meningkatkan keterlibatan pengguna, serta dapat menekan kemungkinan kesalahan [7].

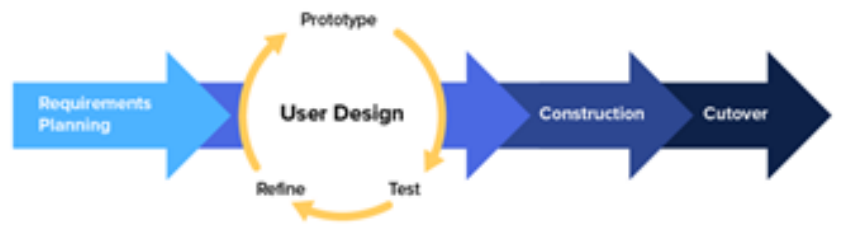

Sumber : [8]

Gbr.1. Model Rapid Application Development (RAD)

Dalam model ini ada beberapa tahapan pengembangan sistem yaitu [8]:

1. Rencana Kebutuhan (Requirements Planning)

Pada tahap ini pengguna dan penulis saling bertemu untuk meneliti dan memecahkan masalah yang sedang terjadi, menentukan apa saja yang dibutuhkan untuk membuat sistem aplikasi, karena tahap ini merupakan langkah awal keberhasilan pembuatan sistem serta dapat menghidari kesalahan komunikasi antara pengguna dan penulis.

2. Desain Pengguna (User Design)

Tahap membuat rancangan yang akan diusulkan agar sesuai dengan kebutuhan, berjalan sesuai rencana dan diharapkan dapat mengatasi masalah yang sedang terjadi. Pada penelitian ini, desain sistem yang digambarkan menggunakan Tools Unified Modeling Language (UML).

3. Construction

Tahap ini adalah tahap memulai membuat sistem yang sudah direncakanan. Memulai menyusun suatu kode program atau biasa disebut coding, untuk merubah desain sistem yang telah dibuat menjadi sebuah aplikasi yang telah direncanakan agar dapat digunakan.

4. Cutover

Tahap ini adalah pengujian keseluruhan sistem yang dibangun semua komponen perlu diuji secara menyeluruh dengan Black Box Testing supaya dapat mengurangi risiko cacat sistem. Black-Box Testing merupakan teknik pengujian perangkat lunak yang berfokus pada spesifikasi fungsional dari perangkat lunak [9].

\section{HASIL DAN PEMBAHASAN}

\section{A. Prosedur Pengolahan Data Rapor Sistem Berjalan}

Prosedur pengolahan data rapor diawali dengan proses pengisian rapor. Pada proses pengisian rapor bagian staf tata usaha membuat file leger nilai mata pelajaran, rekap absensi, rekap ekstrakurikuler dan rapor dalam format excel untuk diberikan kepada guru mata pelajaran dan wali kelas. guru mata pelajaran mengisi nilai-nilai siswa ke dalam file leger tersebut. jika semua guru mata pelajaran telah selesai mengisi nilai siswa, tahap selanjutnya adalah guru mata pelajaran memberikan file leger tersebut ke masing-masing wali kelas. wali kelas akan mengecek kembali nilai yang telah dimasukan oleh guru mata pelajaran. selanjutnya setiap wali kelas memasukan nilai masing-masing siswa ke dalam file rapor, nilai per mata pelajaran, nilai kepribadian berupa nilai sikap, nilai extrakurikuler dan nilai absen siswa. selanjutnya jika wali kelas telah selesai mengisi nilai siswa ke dalam file rapor, wali kelas memberikan file rapor kepada staf tata usaha. setelah staf tata usaha menerima file rapor dari wali kelas selanjutnya adalah staf tata usaha mencetak rapor siswa. kemudian hasil rapor yang telah dicetak diberikan kembali kepada masingmasing wali kelas untuk dicek kembali dan ditanda tangani oleh wali kelas. setelah rapor mengetahui dan ditanda tangan oleh kepala sekolah, rapor siap dibagikan kepada wali murid siswa.

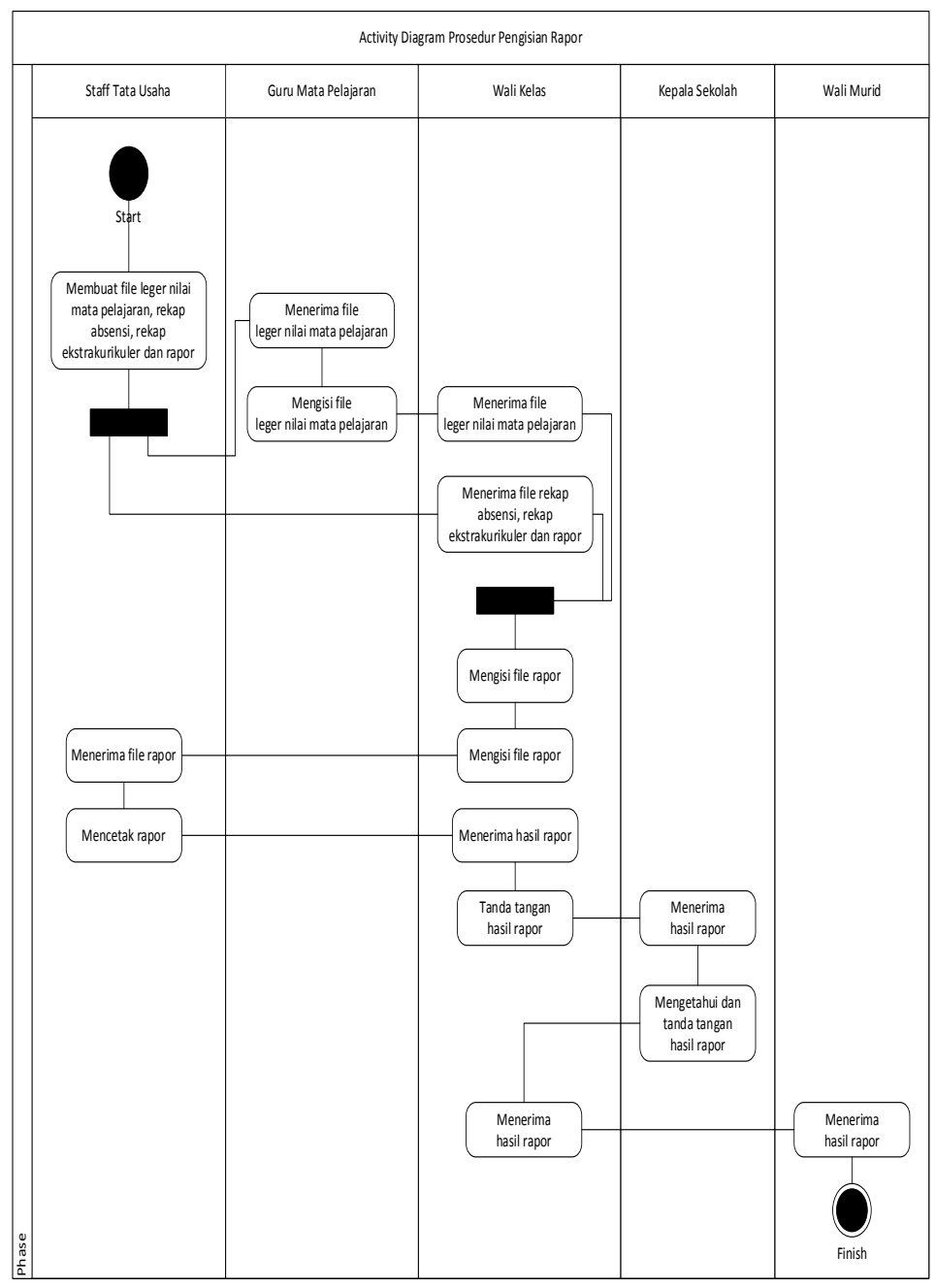

Sumber : Penjelasan Staff Tata Usaha SD Islam Imam Syafi’i

Gbr.2. Activity Diagram Prosedur Pengolahan Data Rapor

B. Rancangan Sistem Usulan

\section{Requirements Planning}

Requirements Planning atau project requirements biasanya berisikan apa saja yang harus dicapai dalam sebuah proyek dan strategi untuk menghadapi permasalahan yang mungkin akan muncul [10]. 
Pada bagian ini diuraikan tentang kebutuhan fungsional software yang disertai dengan penggambaran Use case diagram dan Activity diagram yang terkait dengan proses pengolahan nilai rapor yang dibutuhkan.

Untuk dapat membuat sistem yang dapat mengatasi permasalahan yang ada, maka langkah pertama yang harus dilakukan adalah mengidentifikasi kebutuhan pengguna yang akan menggunakan aplikasi ini nantinya. Tahapan ini sangat penting karena perlu adanya sudut pandang dari pengguna dalam menentukan bagaimana sistem yang sebenarnya dibutuhkan oleh pengguna [11]. Sehingga akan mempermudah penulis dalam pembuatan sistem informasi sesuai kebutuhan user atau pengguna.

Sistem Informasi Rapor Online merupakan sebuah sistem informasi yang berfungsi untuk mengelola nilai siswa disetiap akhir semester. Spesifikasi kebutuhan (system requirement) dari Sistem Informasi Rapor Online (SIRALINE) terdiri dari :

a) Halaman Admin, yang meliputi proses melakukan loginlogout, melihat halaman utama, mengubah profil, mengelola data admin, mengelola data siswa, mengelola data guru, mengelola data walikelas, mengelola kurikulum sekolah, dan mencetak rapor.

b) Halaman Guru, yang meliputi proses melakukan loginlogout, mengubah profil, mengelola kompetensi, dan mengelola nilai siswa.

c) Halaman Wali Kelas, yang meliputi proses login- logout, mengubah profil, mengelola rapor, dan melihat rapor.

d) Halaman Developer, yang meliputi proses melakukan login-logout, melihat halaman utama, mengubah profil, mengelola data admin, mengelola data siswa, mengelola data guru, mengelola data walikelas, mengelola kurikulum sekolah, mengelola data walikelas, mengelola hak akses, dan mengelola menu.

\section{1) Use case Diagram}

Use case diagram menggambarkan fungsionalitas yang diharapkan dari sebuah system [12]. Use Case Diagram juga merupakan gambaran grafis dari beberapa atau semua actor, use case, dan interaksi diantaranya yang memperkenalkan suatu sistem. Use case diagram tidak menjelaskan secara detil tentang penggunaan use case, tetapi hanya memberi gambaran singkat hubungan antara use case, aktor, dan system [13].

a) Use case Diagram Admin

Use case diagram admin menggambarkan apa yang dilakukan admin untuk mengakses menu yang terdapat pada sistem.

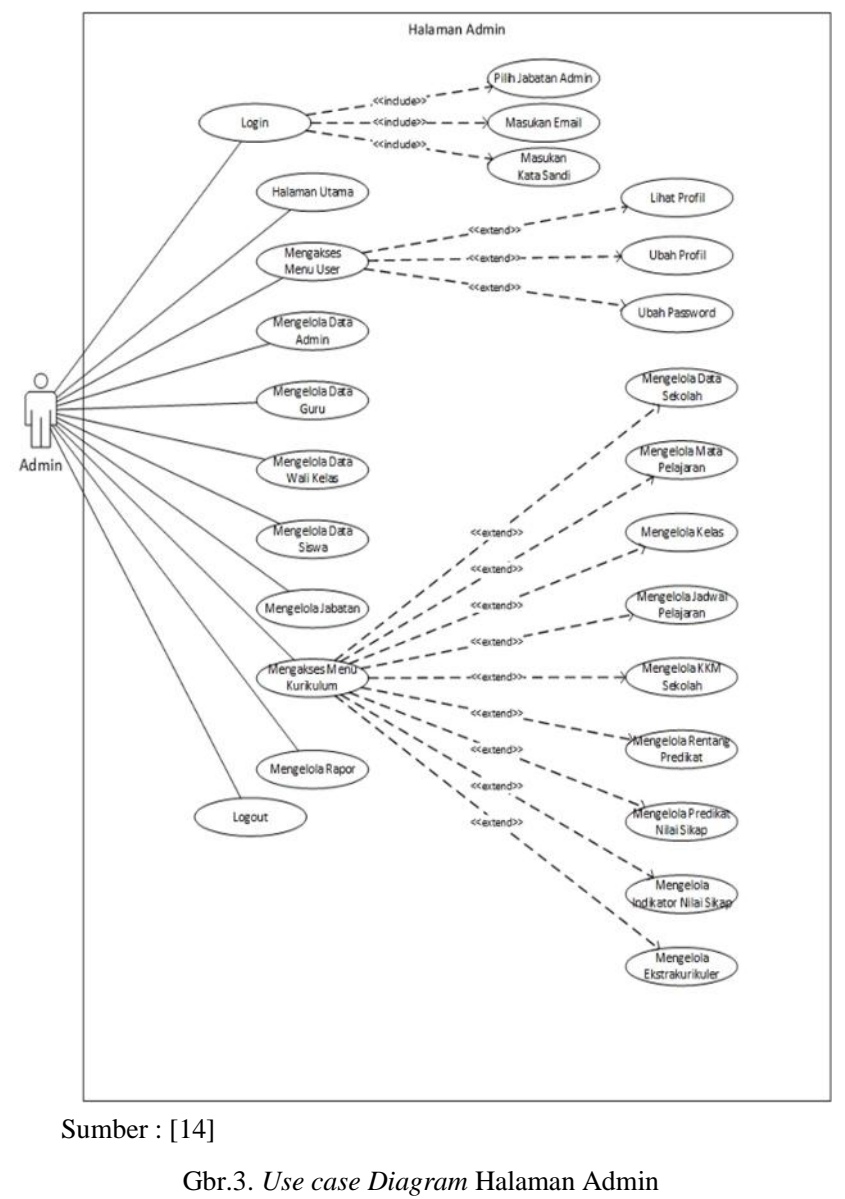

b) Use case Diagram Guru

Use case diagram guru menggambarkan apa yang dilakukan guru untuk mengakses menu yang terdapat pada sistem.

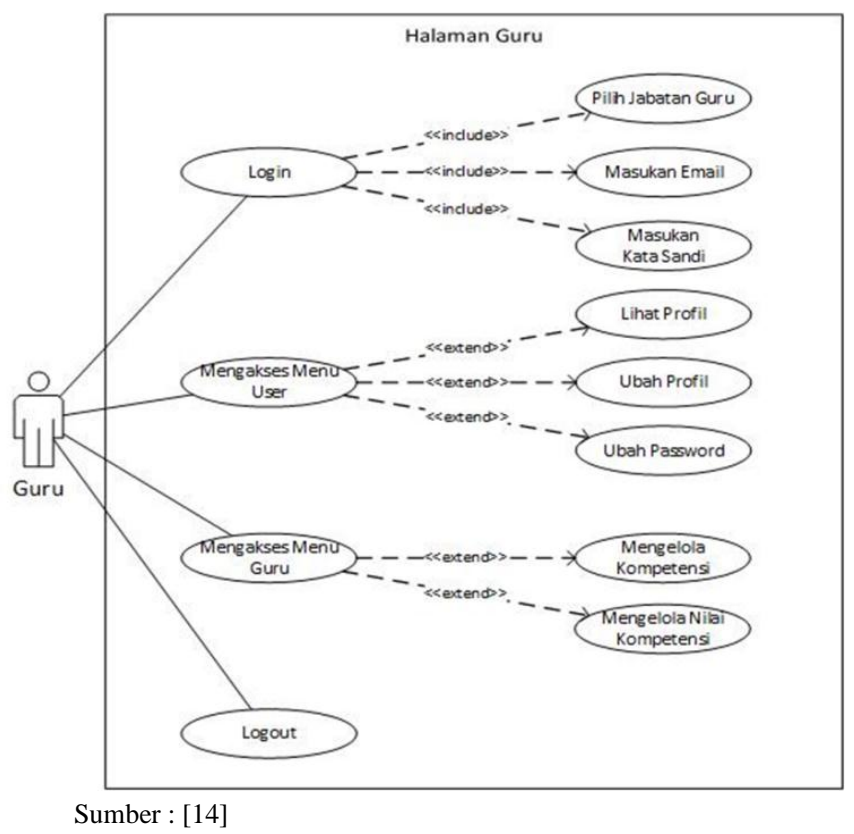

Gbr.4. Use case Diagram Halaman Guru 
c) Use case Diagram Wali Kelas

Use case diagram wali kelas menggambarkan apa yang dilakukan wali kelas untuk mengakses menu yang terdapat pada sistem.

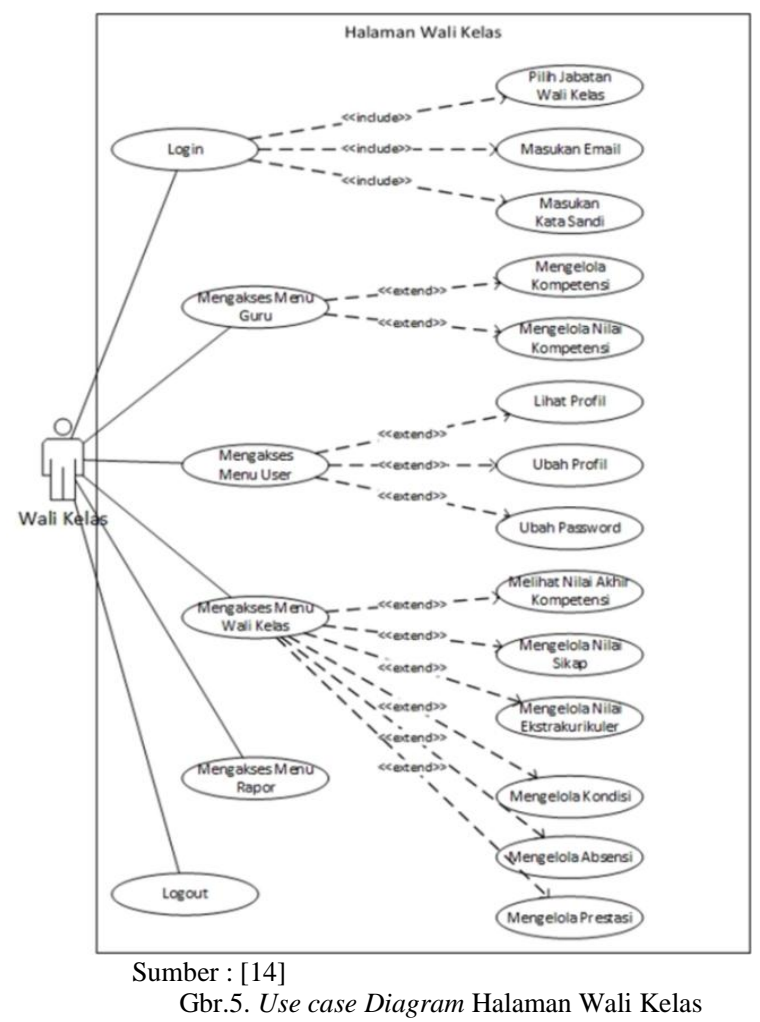

d) Use case Diagram Developer

Use case diagram developer menggambarkan apa yang dilakukan developer untuk mengakses menu yang terdapat pada sistem.

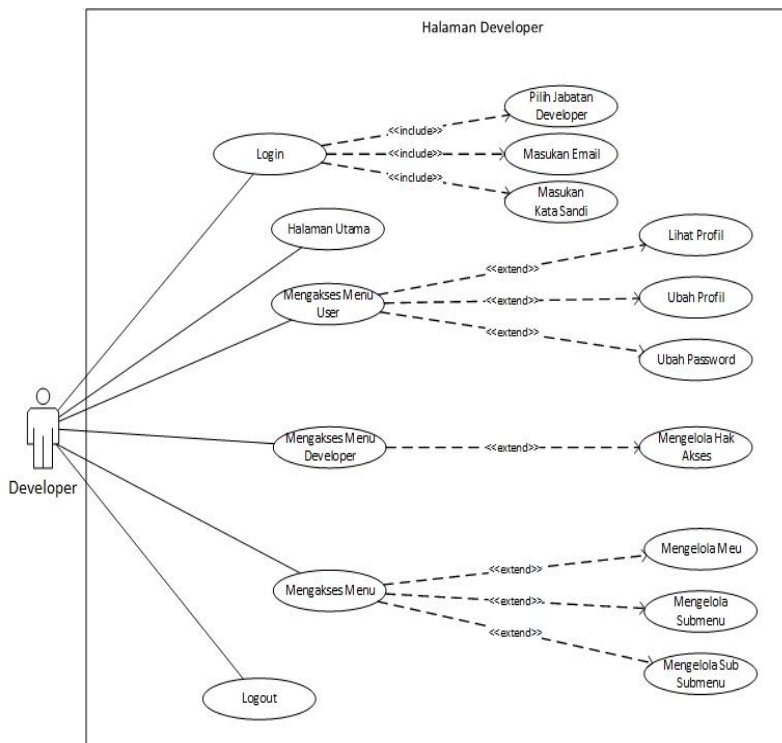

Sumber : [14]

Gbr.6. Use case Diagram Halaman Developer
2) Activity Diagram

Activity diagrams menggambarkan berbagai alir aktivitas dalam sistem yang sedang dirancang, bagaimana masingmasing alir berawal, decision yang mungkin terjadi, dan bagaimana mereka berakhir [12].

a) Activity Diagram Mengelola KKM Sekolah

Activity Diagram mengelola Kriteria Ketuntasan Minimal (KKM) menggambarkan apa yang dilakukan Admin untuk dapat melihat data detail KKM.

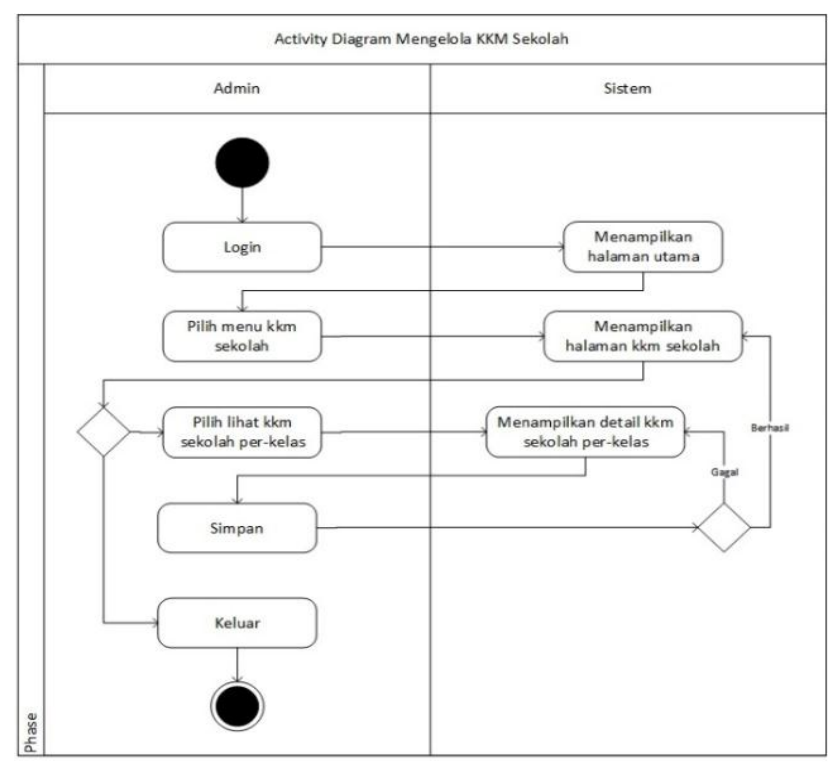

Sumber : [14]

Gbr 7. Activity Diagram Mengelola KKM Sekolah

b) Activity Diagram Mengelola Rapor

Activity Diagram mengelola rapor menggambarkan apa yang dilakukan Admin untuk dapat melihat rapor per kelas serta dan mencetak rapor per siswa.

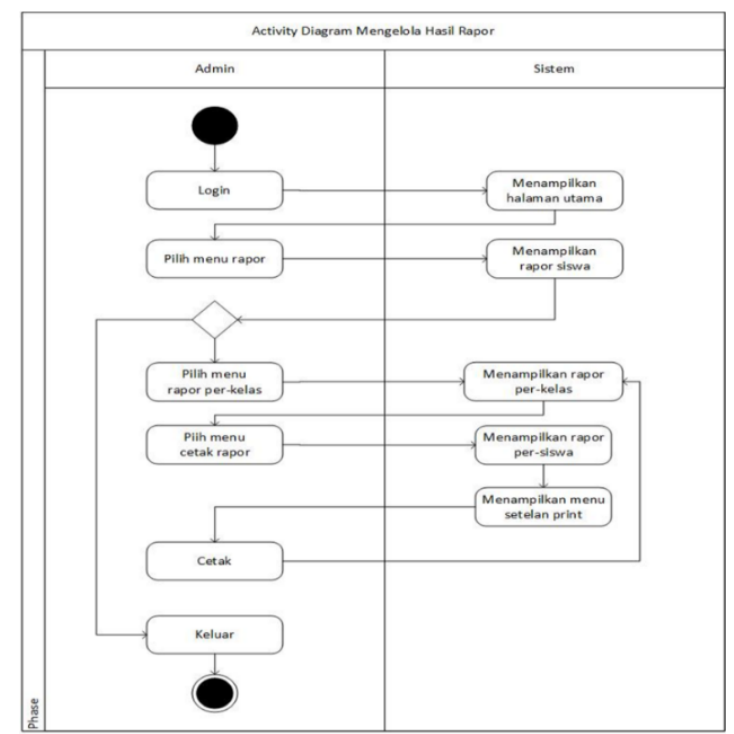

Sumber : [14]

Gbr 8. Activity Diagram Mengelola Rapor 
c) Activity Diagram Mengelola Kompetensi Activity Diagram mengelola kompetensi menggambarkan apa yang dilakukan oleh Guru untuk dapat mengelola data kompetensi, yang meliputi kegiatan menampilkan deskripsi kompetensi per mata pelajaran dan per kelas, serta menambah, mengubah, dan menghapus data kompetensi.

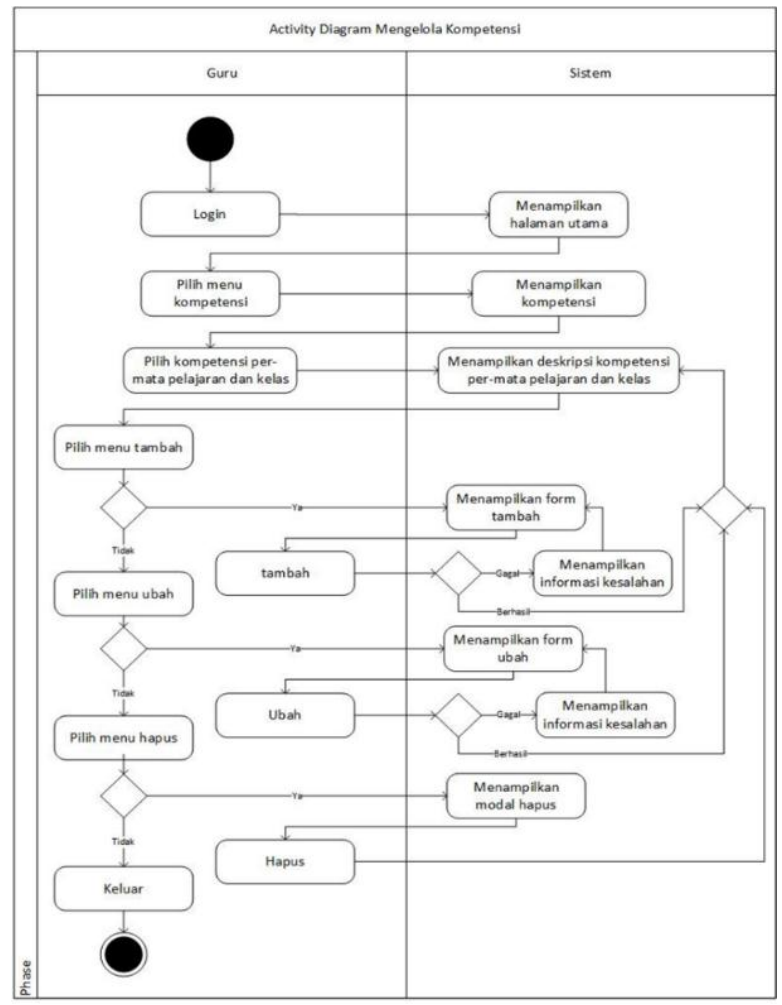

Sumber : [14]

Gbr 9. Activity Diagram Mengelola Kopetensi

d) Activity Diagram Nilai Akhir Kompetensi

Activity Diagram nilai akhir kompetensi ini menggambarkan apa yang dilakukan oleh Wali Kelas untuk dapat melihat nilai akhir kompetensi.

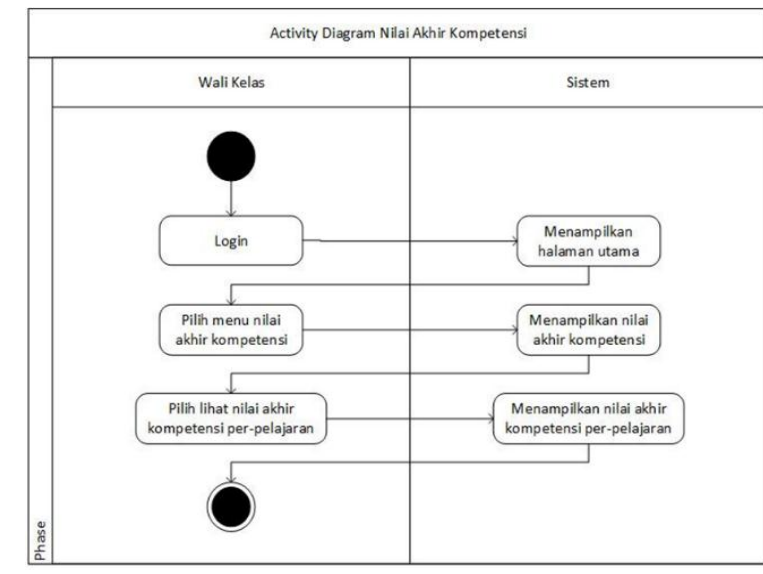

Sumber : [14]

Gbr 10. Activity Diagram Nilai Akhir Kopetensi
3) Sequence Diagram

Sequence diagram menggambarkan interaksi antar objek di dalam dan di sekitar sistem (termasuk pengguna, display, dan sebagainya) berupa message yang digambarkan terhadap waktu [12].

a) Sequence Diagram Halaman Login

Sequence Diagram halaman login menggambarkan apa yang dilakukan pengguna untuk dapat login masuk kedalam system. Dimulai dari user melakukan login pada form login dan memilih jabatan, validasi data login hingga pengguna dapat masuk pada halaman utama sistem.

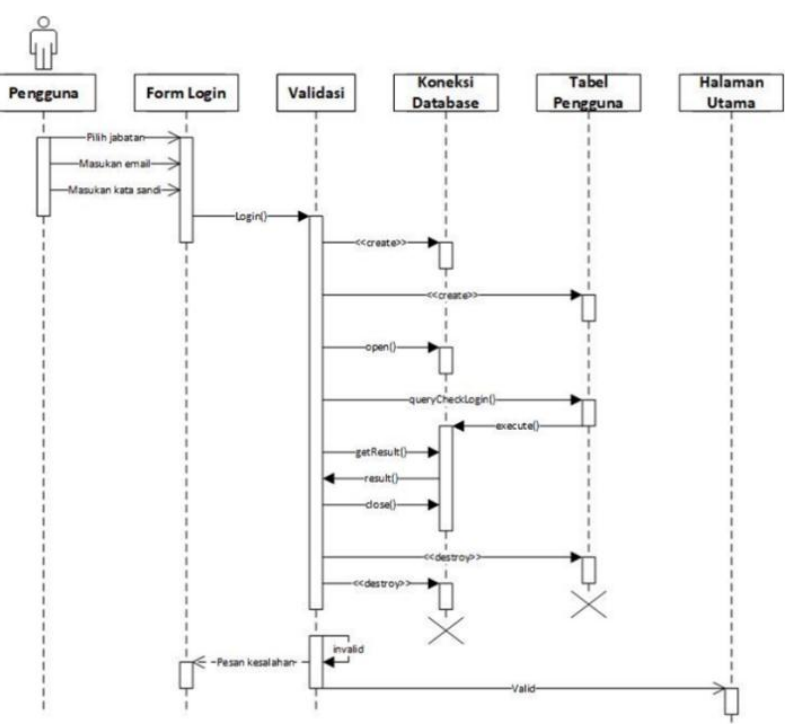

Sumber : [14]

Gbr 12. Sequence Diagram Halaman Login

b) Sequence Diagram Halaman KKM

Sequence Diagram halaman KKM menggambarkan apa yang dilakukan admin untuk dapat megelola data KKM. Dimulai dari admin memilih menu KKM, memilih KKM perkelas, serta mengisi data KKM.

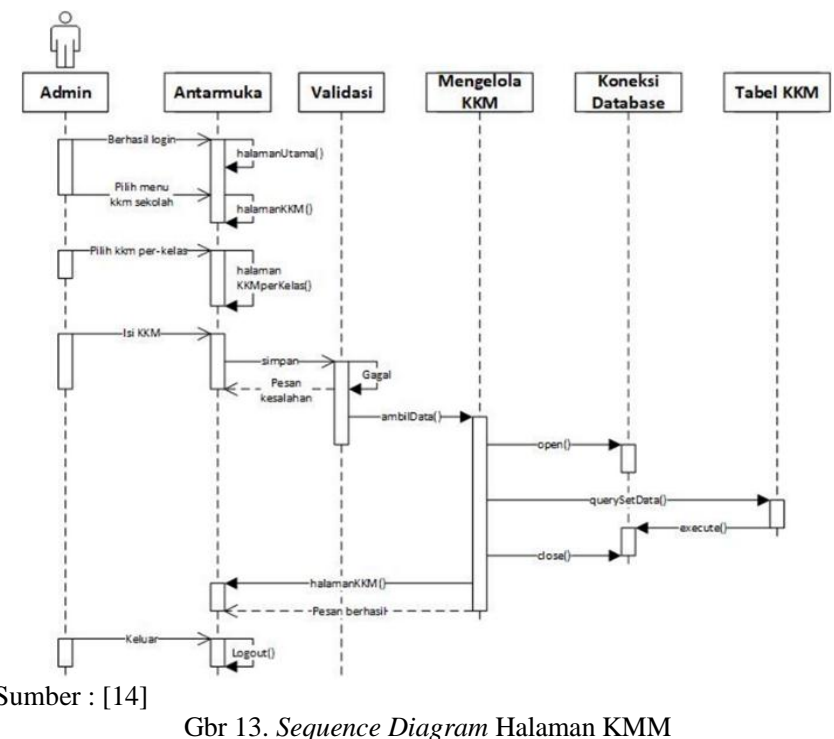


c) Sequence Diagram Halaman Nilai Kompetensi Sequence Diagram halaman Nilai Kompetensi pada gambar 14 menjelaskan apa yang dilakukan guru untuk dapat mengelola nilai kompetensi. Dimulai dari guru memilih menu nilai kompetensi, memilih nilai kompetensi per mata pelajaran dan perkelas, serta melakukan pengolahan tambah, ubah dan hapus data nilai kompetensi. Dimana pengolahan data terebut akan tersimpan pada table Nilai Kompetensi.

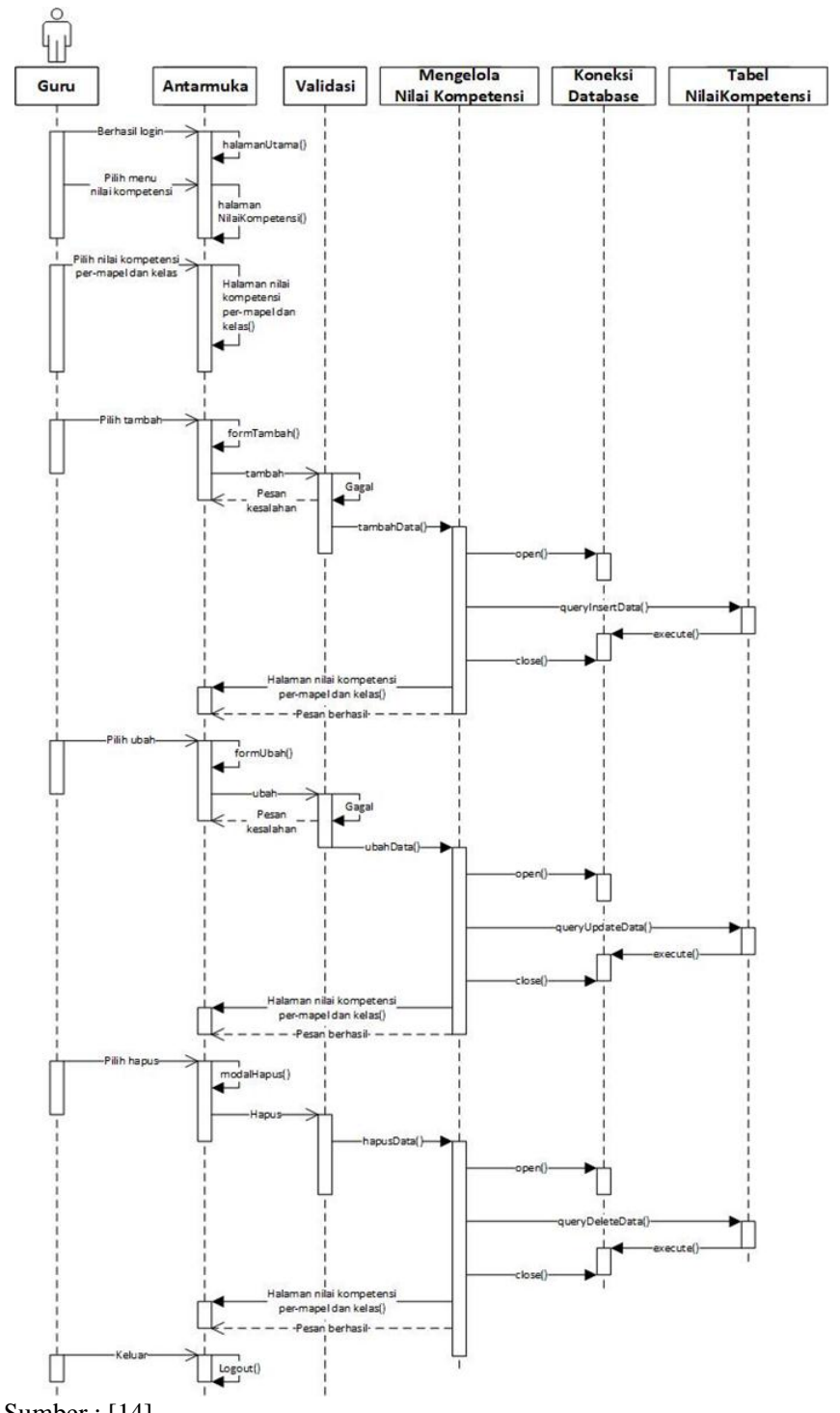

Sumber : [14]

Gbr 14. Sequence Diagram Halaman Nilai Kompetensi

d) Sequence Diagram Halaman Nilai Akhir Kompetensi Sequence Diagram halaman Nilai Akhir Kompetensi menggambarkan apa yang dilakukan oleh wali kelas untuk dapat mengelola nilai akhir kompetensi dan melihat nilai akhir kompetensi.

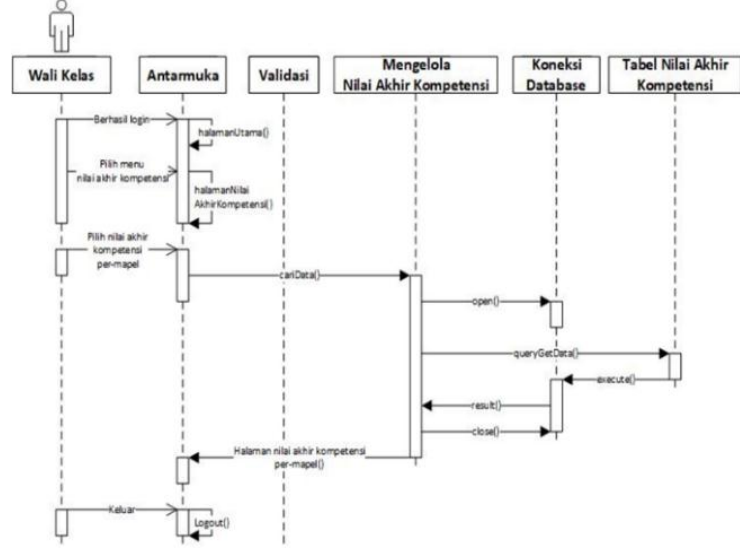

Sumber : [14]

Gbr 15. Sequence Diagram Halaman Nilai Akhir Kompetensi

4) Class Diagram

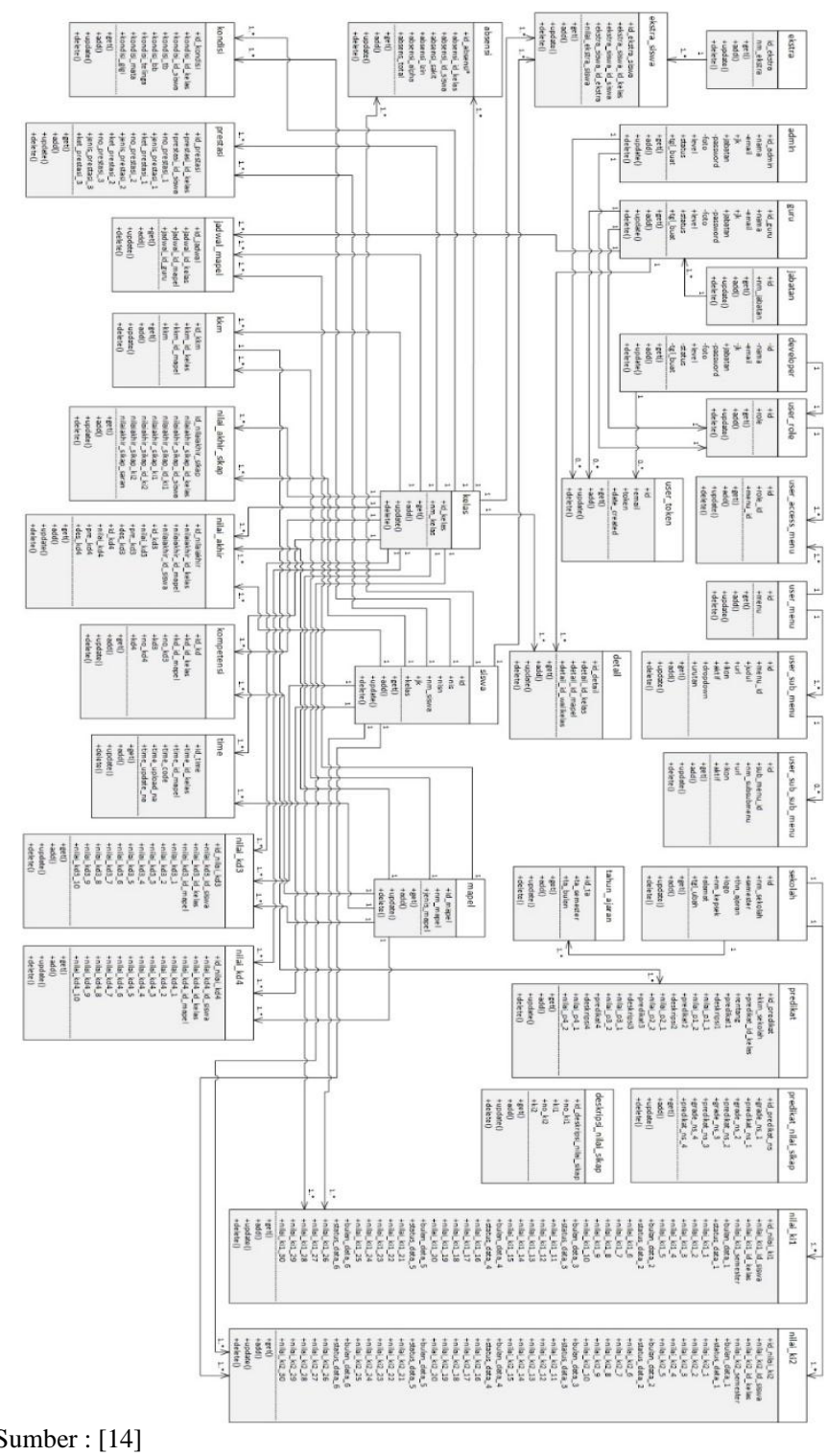

Gbr 11. Class Diagram 
Class diagram merupakan salah satu diagram utama dari UML untuk menggambarkan class atau blueprint object pada sebuah system [15]. Class diagram pada gambar 11 menunjukan domain model class yang membentuk system informasi rapor online.

\section{5) Component Diagram}

Componen Diagram merupakan bagian fisik system yang bersesuaian dan menyediakan realisasi dari sekumpulan interface[16]. Pada penelitian ini, komponen yang bersesuaian dengan Sisem Informasi Rapor Online (SIRALINE) adalah database ci_sdiisj yang dibuat dengan alikasi MySQL dan Apache. Selain itu adanya software pendukung aplikasi yang digunakan oleh user.

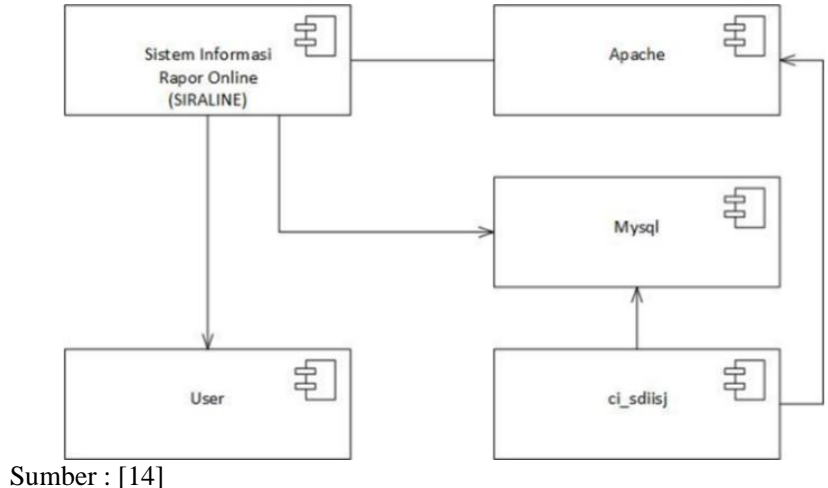

Gbr 16. Component Diagram

6) Deployment Diagram

Deployment diagram digunakan untuk memvisualisasikan hubungan antara software dan hardware [17]. Deployment diagram penelitian ini menunjukan visualisasi komponen dalam proses eksekusi aplikasi Website SIRALINE, yang didalamnya berhubungan dengan database server serta Web browser yang digunakan oleh user.

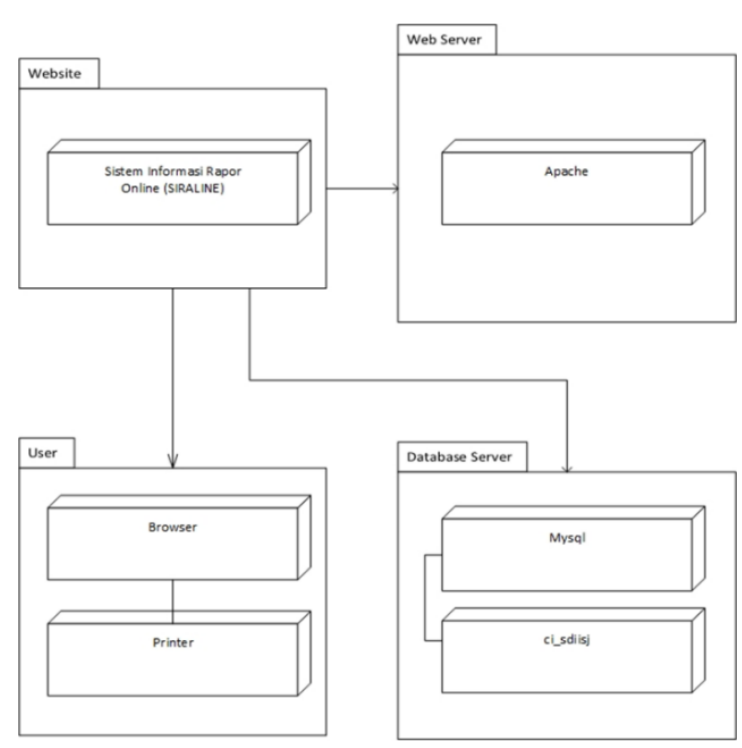

Gbr 17. Deployment Diagram

\section{Desain Pengguna (User Design)}

Disain pengguna merupakan tahap membuat rancangan yang akan diusulkan agar sesuai dengan kebutuhan, dan berjalan sesuai rencana dan diharapkan sehingga dapat mengatasi masalah yang sedang terjadi .

User Interface (UI) berfokus pada mengantisipasi apa yang mungkin dilakukan oleh pengguna dan memastikan bahwa antarmuka memiliki elemen yang mudah diakses, dipahami, dan digunakan untuk memfasilitasi tindakan pengguna [18].

a) User Interface Halaman Login

Menggambarkan form yang digunakan oleh pengguna (user) untuk dapat mengakses Sisem Informasi Rapor Online (SIRALINE)

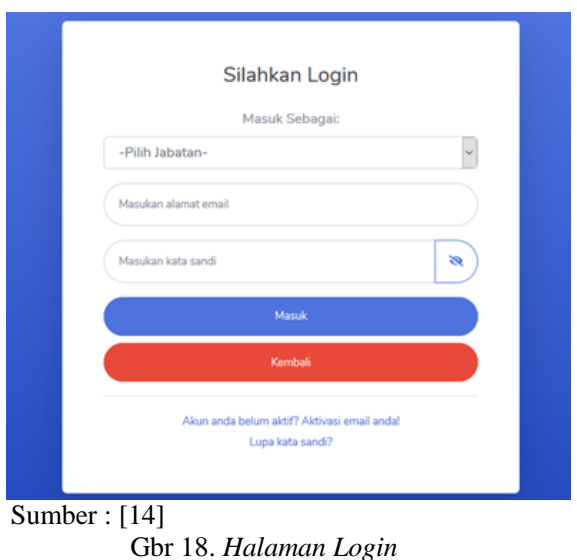

b) User Interface Halaman Detail KMM Sekolah Menggambarkan halaman yang digunakan oleh admin untuk dapat mengelola data Kriteria Ketuntasan Miniman (KKM)
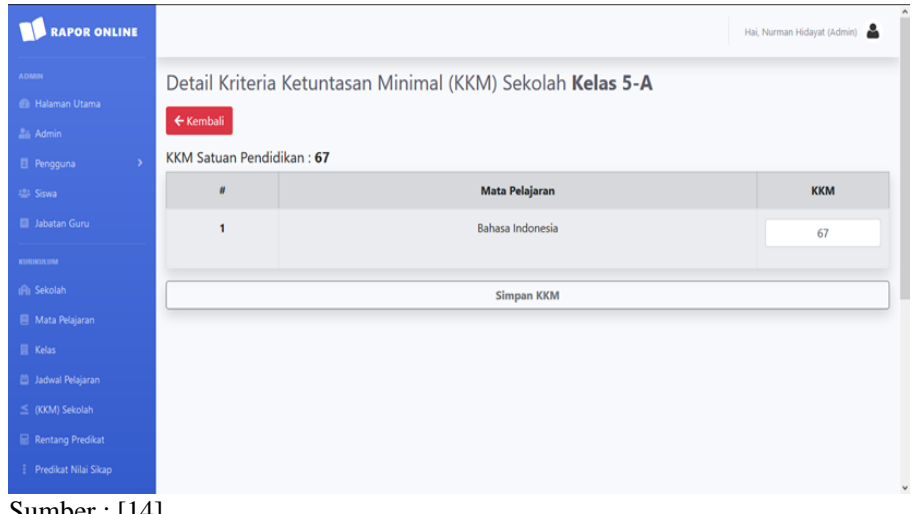

Gbr 19. Halaman Detail KMM

c) User Interface Halaman Detail Nilai Akhir Kompetensi Menggambarkan halaman yang digunakan oleh guru untuk dapat mengelola data Nilai akhir kompetensi. 


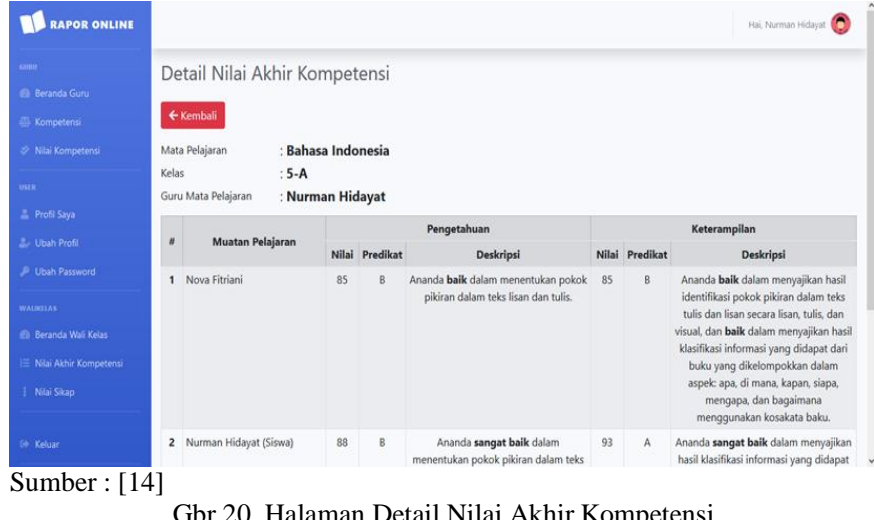

Gbr 20. Halaman Detail Nilai Akhir Kompetensi

\section{d) User Interface Halaman Rapor}

Menggambarkan Form tampilan rapor online.

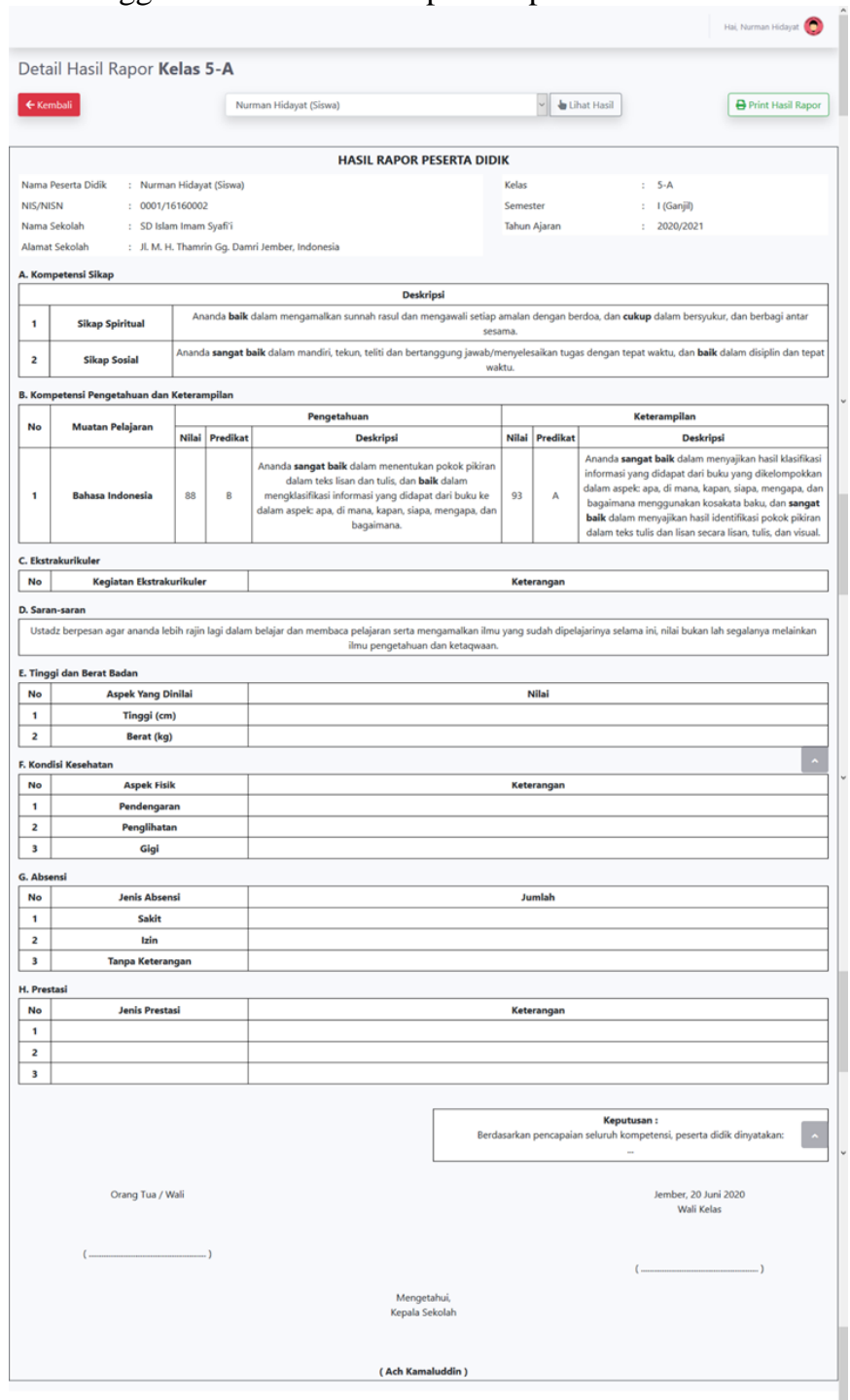

Sumber : [14]

Gbr 21. Halaman Rapor

\section{Construction}

Contruction merupakan tahap pada RAD dimana pengembang bekerja secara langsung dengan user, membuat rancangan akhir, membangun dan menguji prototype. Hasil keluaran tahapan ini adalah dokumentasi dan instruksi yang penting untuk mengoperasikan aplikasi baru dan prosedur yang diperlukan agar sistem dapat beroperasi [19].

Pada tahap ini penulis mulai membuat sistem yang sudah direncakanan dengan menyusun kode program atau coding, untuk merubah desain sistem yang telah dibuat menjadi sebuah aplikasi yang telah direncanakan agar dapat digunakan. Aplikasi yang dibuat menggunakan Codeigniter 3 untuk framework, PHP untuk bahasa pemrograman, MySQL untuk database dan Visual Studio Code sebagai tools yang membantu pembuatan sistem informasi tersebut

\section{Cutover}

Tahap ini adalah tahap pengujian keseluruhan sistem yang dibangun. Semua komponen perlu diuji secara menyeluruh. Pada penelitian ini, pengujian dilakukan dengan menggunakan black box testing, dimana pengujian ini lebih menguji ke Tampilan Luar (interface) dari suatu aplikasi agar mudah digunakan oleh Customer. Black box testing bekerja dengan mengabaikan struktur control sehingga perhatianya hanya terfokus pada informasi domain [20].

\section{KESIMPULAN}

Akhir dari penulisan ini adalah bahwa teknologi informasi sangat penting dan berpengaruh dalam kehidupan sehari-hari khususnya didalam dunia Pendidikan.

Selain itu, kesimpulan yang dapat dilihat dari penulisan bab-bab sebelumnya adalah perancangan sistem informasi rapor online ini dapat menghasilkan :

a. Sistem informasi berbasis web sebagai media online data akademik pengolahan rapor SD Islam Imam Syafi'i dengan memberikan informasi yang dibutuhkan secara cepat dan tepat.

b. Sistem informasi rapor online ini dapat membantu pengolahan dan pengarsipkan data rapor yaitu: data sekolah, data guru, data wali kelas, data siswa, data akademik dan nilai siswa.

c. Sistem informasi pada SD Islam Imam Syafi'i dapat mempermudah proses pengolahan rapor yang sebelumnya prosesnya masih manual menggunakan file excel.

\section{REFERENSI}

[1] J. Hutahaean, Konsep Sistem Informasi. Yogyakarta: Deepublish, 2014.

[2] N. ahlung arniyanto Putri and angit dwi Hartanto, "YOGYAKARTA BERBASIS WEB Pendahuluan Landasan Teori," J. Ilm. DASI, vol. 14, no. 04, pp. 38-43, 2013. 
[3] A. Hidayat, "METODE PENELITIAN: Pengertian, Tujuan, Jenis," statistikian.com https://www.statistikian.com/2017/02/metode-penelitianmetodologi-penelitian.html.

[4] S. Aswati, M. S. Ramadhan, A. U. Firmansyah, and K. Anwar, "Studi Analisis Model Rapid Application Development Dalam Pengembangan Sistem Informasi," J. Matrik, vol. 16, no. 2, p. 20, 2017, doi: 10.30812/matrik.v16i2.10.

[5] D. S. Budi, T. A. Y. Siswa, and H. Abijono, "Analisis Pemilihan Penerapan Proyek Metodologi Pengembangan Rekayasa Perangkat Lunak," Teknika, vol. 5, no. 1, pp. 24-31, 2017, doi: 10.34148/teknika.v5i1.48.

[6] A. Kusnanjaya, "Rancang Bangun Sistem Informasi Data Guru Menggunakan Metode Rapid Application Development," PILAR Nusa Mandiri, vol. IX, no. 2, pp. 147-152, 2013.

[7] Vlado, "Rapid Application Development (RAD)," adikristanto.net, 2010. https://adikristanto.net/rapidapplication-development-rad/ (accessed Mar. 10, 2020).

[8] kissflow, "Rapid Application Development: Changing How Developers Work," 31 Oktober, 2018. https://kissflow.com/rad/rapid-application-development/ (accessed Apr. 11, 2020).

[9] T. S. Jaya, "Pengujian Aplikasi dengan Metode Blackbox Testing Boundary Value Analysis (Studi Kasus: Kantor Digital Politeknik Negeri Lampung)," J. Inform. J. Pengemb. IT, vol. 3 , no. 2, p. 45, 2018, [Online]. Available: http://www.ejournal.poltektegal.ac.id/index.php/informatika/ar ticle/view/647/640.

[10] Glints, "Rapid Application Development, Metode Pengembangan Software yang Hemat Waktu," glints.com 3020. https://glints.com/id/lowongan/rapid-applicationdevelopment-adalah/\#.X5EFvtAzaM8 (accessed Sep. 25, 2020).

[11] Elisabeth, "Bagaimana cara melakukan identifikasi kebutuhan pengguna?," dictio.id. https://www.dictio.id/t/bagaimana-caramelakukan-identifikasi-kebutuhan-pengguna/18911 (accessed Apr. 22, 2020).

[12] S. Dharwiyanti and R. S. Wahono, "Pengantar Unified Modeling Language (UML)," IlmuKomputer.com, pp. 1-13, 2003, [Online]. Available: http://www.unej.ac.id/pdf/yantiuml.pdf.

[13] A. R. Pratama, "Belajar UML - Use Case Diagram," 21 Januari 2019, 2019. https://www.codepolitan.com/mengenaluml-diagram-use-case.

[14] N. Hidayat, "Penggunaan Framework Codeigniter 3 dalam Rancang Bangun Sistem Informasi Rapor Online (Siraline) pada SD Islam Imam Syafi'i Jember," STMIK Antar Bangsa, 2020.

[15] C. N. Tanuwijaya, "Domain Class Diagram," Binus University, $2016 . \quad$ https://sis.binus.ac.id/2016/06/20/domain-classdiagram/.

[16] S. Atmadjaja, "Komponen dan Deployment diagram." slideplayer.info, 2017, [Online]. Available: https://slideplayer.info/slide/12126919/.

[17] Nur Anisa, "Perbedaan Deployment Diagram Dan Component Diagram,"sis.binus.ac.id,2020. https://sis.binus.ac.id/2020/04/20/perbedaan-deploymentdiagram-dan-component-diagram/ (accessed Oct. 26, 2020).

[18] techfor.id, "Fungsi User Interface (UI) dalam membangun Desain yang Optimal," techfor.id, 2020 https://www.techfor.id/fungsi-user-interface-ui-dalammembangun-desain-yang-optimal/ (accessed Oct. 26, 2020).

[19] D. Yen and W. Davis, "Rapid application development (RAD)," Inf. Syst. Consult. Handb., 1998, doi: 10.1201/9781420049107.ch32.

[20] I. K. Wairooy, "Teknik Dalam White-box dan Black-box Testing," socs.binus.ac.id, 2020 https://socs.binus.ac.id/2020/07/02/teknik-dalam-white-boxdan-black-box-testing/ (accessed Oct. 26, 2020).

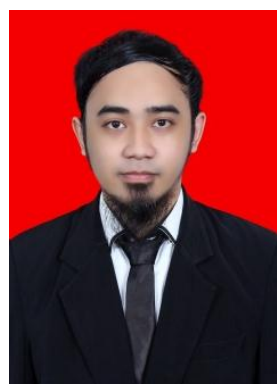

Nurman Hidayat. Lahir di Surabaya, pada tanggal 22 Februari 1995. Tahun 2020 lulus Program Sarjana Strata Satu (S1) Jurusan Sistem Informasi di STMIK Antar Bangsa.

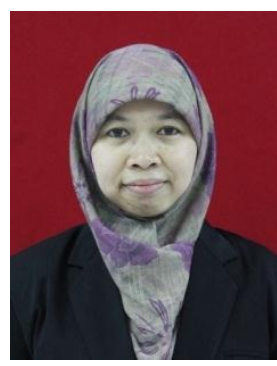

Kusuma Hati. Lahir di Jakarta, pada Tanggal 21 Maret 1974. Lulus Program Strata Satu (S1) Jurusan Manajemen Informatika, Universitas Gunadarma Jakarta pada Tahun 1997. Tahun 2006 lulus Program Pasca Sarjana Magister Manajemen, Universitas Budi Luhur. Tahun 2013 Lulus Program Pasca Sarjana Magister Komputer, STMIK Nusa Mandiri Jakarta. Saat ini aktif sebagai Dosen Tetap di STMIK Antar Bangsa. Aktif juga sebagai peneliti dan penulis jurnal ilmiah, serta nggota Asosiasi Perguruan Tinggi Ilmu Komputer (APTIKOM) dan Asosiasi Dosen Indonesia (ADI). 